\title{
VESTIDA DE INFÂNCIA
}

Claudia Tavares é artista visual e doutoranda em Processos Artísticos Contemporâneos pelo Instituto de Artes da UERJ. Leciona atualmente no Ateliê da Imagem. E-mail: claudia@claudiatavares.com

\section{Resumo}

Este ensaio propõe apresentar um grupo de seis trabalhos que constituem a exposição intitulada Vestida de Infância. A partir do materialidade de vestidos pessoais infantis e das questões levantadas pelo reencontro com eles surgem alguns trabalhos que derivam da ideia de corpo, memória, vestimenta, transitoriedade e experimentação. Os trabalhos são atos performativos que constituem ações encenadas para a câmera, em fotografia e vídeo.

\section{Abstract}

This essay proposes to present a group of six works that make up the exhibition entitled Dressed in Childhood. From the materiality of children's personal dresses and the issues raised by the reunion with them come some works that derive from the idea of body, memory, clothing, transience and experimentation. The works are performative acts that constitute staged actions for the camera, by photo and video.

É possível vislumbrar a presença do corpo nu frente à tentativa improvável de cobrir-se com pequenos vestidos, unidos através do encontro insólito de casas e botões. A soma dessas pequenas partes, a formação de uma estrutura maleável e heterogênea, certamente não concebe um todo capaz de abarcar a dimensão geral do corpo. Parte desse organismo fluido, transitório, quase precário, cai por terra frente tal impossibilidade. A imagem registra o encontro desses dois corpos que de algum modo se fundiram, mas não completamente. A presença de motivos florais na superfície desses alvos tecidos, arrematados com delicadas rendas, contrasta com a pequena tatuagem, quase imperceptivel, e as unhas pintadas de vermelho na mão que se apoia no chão. Bordados do tecido, marcas da pele: insígnias do corpo. Vestida de Infância, título da obra, assim como da exposição individual (...), é a porta de entrada para um conjunto de imagens que norteiam essa busca do indivíduo em direção ao reencontro com traços de sua infância.

Ivair Reinaldim. Curador 
À época do nascimento da minha filha, recebi de minha mãe uma sacola de vestidos usados por mim e minhas irmãs na nossa infância, que tinham sido guardados pela minha avó. Uma linda surpresa, um belo presente. Em nenhum momento, no entanto, tive a intenção de vestí-los em Sofia. Pelo contrário, queria eles de volta pra mim. Tentei vesti-los novamente. Não couberam. Tentei unir todos eles, abotoando uns aos outros para criar um único vestido que tivesse a possibilidade de abarcar meu corpo adulto. Tentativa em vão. A infância não me cabe mais.

Assim como as vestimentas que usamos são temporárias e finitas, a infância nos escapa pelo passar do tempo. Invólucros do corpo, as vestes nos protegem da nudez, do frio, do sol e da chuva. Mas vestimentas são membranas porosas. $\mathrm{O}$ que pode ou não passar por essa membrana? Lembranças?Sentimentos?Afetos? A partir do materialidade dos vestidos e das questões levantadas surgem alguns trabalhos que derivam da idéia de corpo, memória, vestimenta, transitoriedade e experimentação. Os trabalhos em fotografia e vídeo são atos performativos que constituem cenas graváveis, ações encenadas para a câmera.

O vídeo Casas para botões, laços e tramas mostra o processo de abotoar, desabotoar e tentar vestir aquilo que não me serve mais em seu estado original. Um ato contínuo de tentativas em vão. $\mathrm{O}$ corpo que um dia foi abrigado por essas vestes já não usufrui do mesmo tamanho. A materialidade dos tecidos é experimentada então por esse corpo presente, atual, que se coloca ao contato dessas recordações, dessas reminiscências. Os tecidos bordados, os laços e botões são característicos não apenas da infância que passou, mas de uma época onde o tempo parecia durar mais. O cuidado exigido por esses vestidos não tem mais cabimento no mundo contemporâneo.

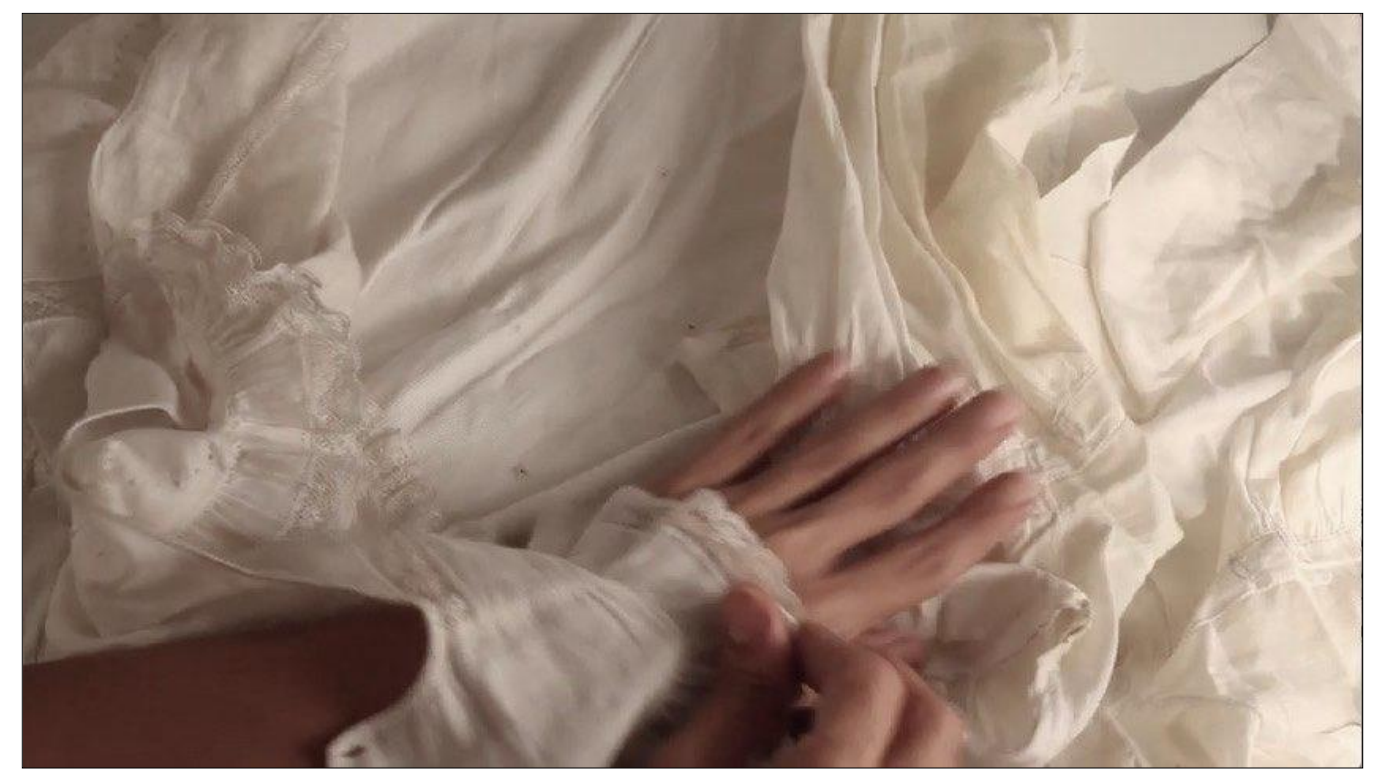



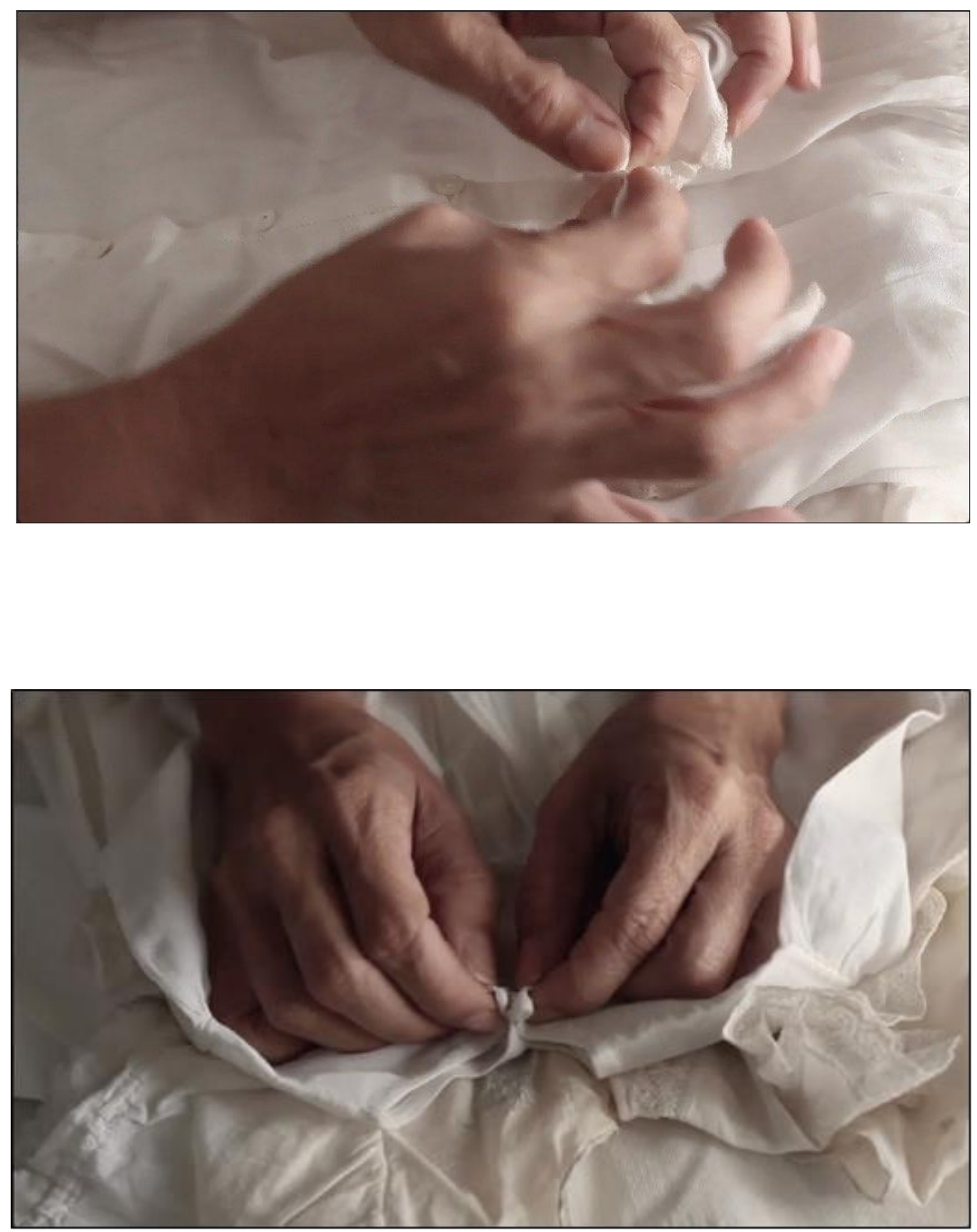
Nos dípticos fotográficos Avesso e Veste Reveste há a predominância do elemento floral proveniente do bordado de um dos vestidos, constituído agora como estampa, tornado um padrão decorativo independente. O bordado se transforma em estampa, padronizado em tatuagens temporárias que agora adornam a pele do corpo adulto.

Em Avesso, a idéia de negativo, como se a pele embaixo do vestido tivesse gravado secretamente seus adornos, por todos ao anos entre o lá e o cá.

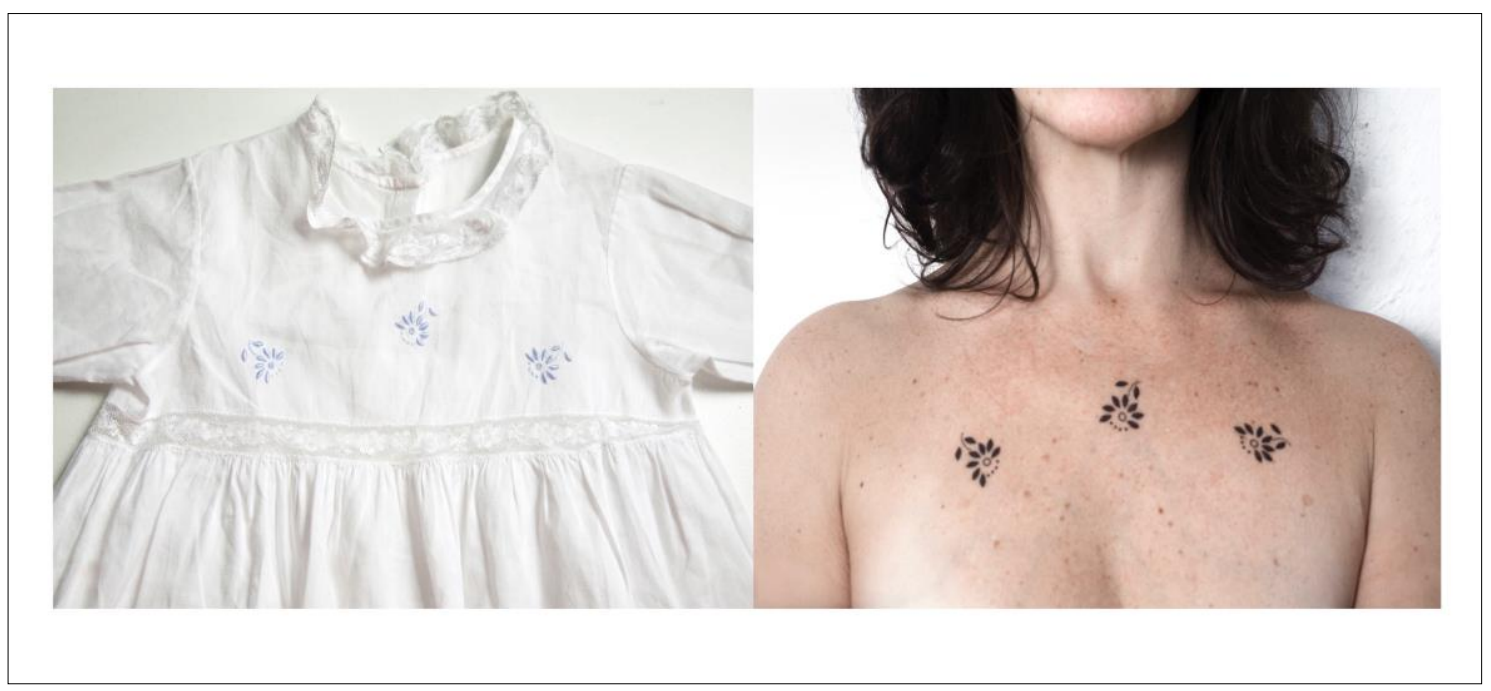

Já em Veste Reveste, o bordado-estampa diverte e tatua o colo na pretensão de criar uma segunda pele agora enfeitada por um padrão decorativo em um livre exercício experimental. A idéia de transformar os padrões dos bordados em tatuagens temporárias é decorrente da noção de memória enquanto algo ficcional, passageiro e mutável. Os desenhos instauram uma nova escrita transitória na pele. Assim como as memórias variam de acordo com o tempo, as tatuagens temporárias sofrem alterações constantes ao longo de sua curta duração.

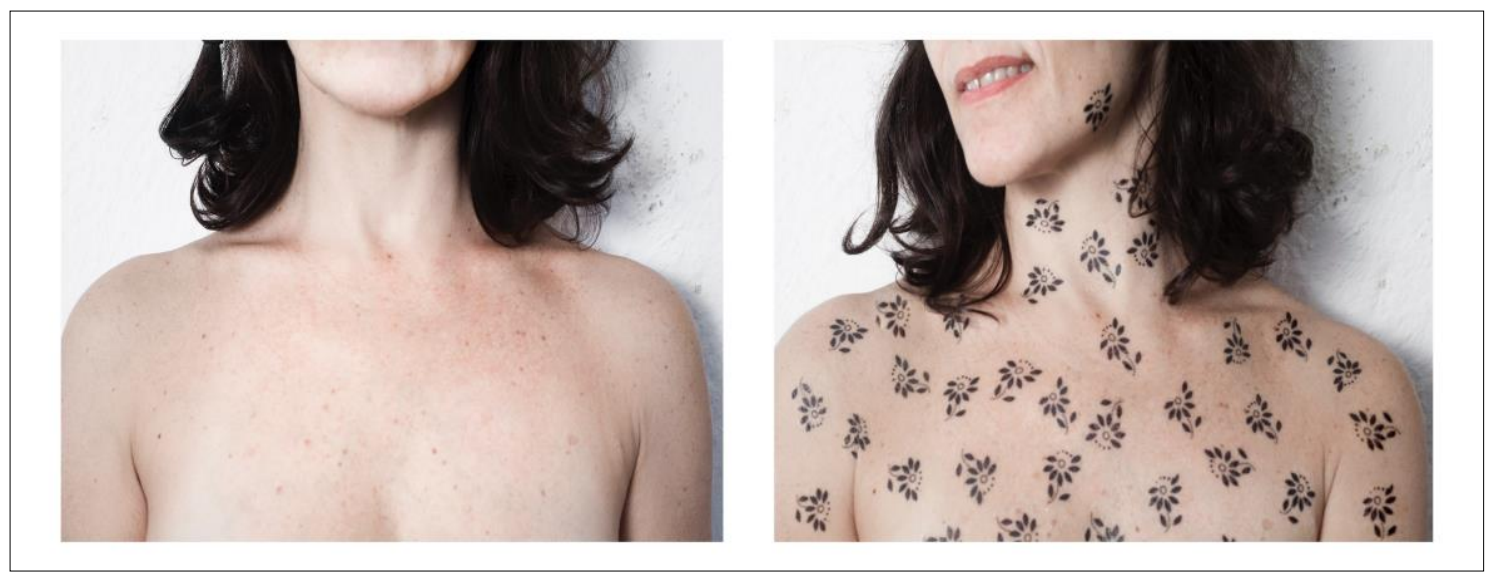


[Des]bordado trata da transitoriedade da memória, onde a água vai apagando o bordado desenhado em lápis aquarela diretamente na pele da mão. O apagamento dessa marca sugere como a memória seleciona certas recordações e apaga outros acontecimentos. De novo uma escrita que vai se apagando do território da pele.

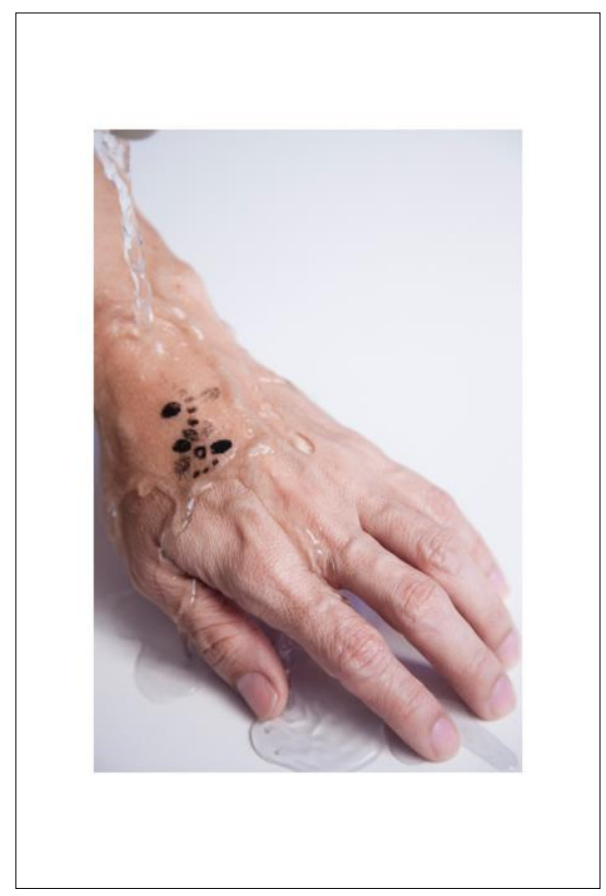

Encerrando a seleção de trabalhos, [Des]casados é o nome de uma série de vestidos-objetos onde se:

apresenta a própria materialidade desses vestidos, meio termo entre objeto e imagem. Decorrentes da união de duas peças distintas, cada proposta da série nasce de uma unidade aparente, porém conflitante, uma vez que suas formas, texturas e bordados não se deixam unificar completamente numa visualidade homogênea. Assim, a soma das partes não constitui o todo, mas reforça sua falta

, avalia Reinaldim. 


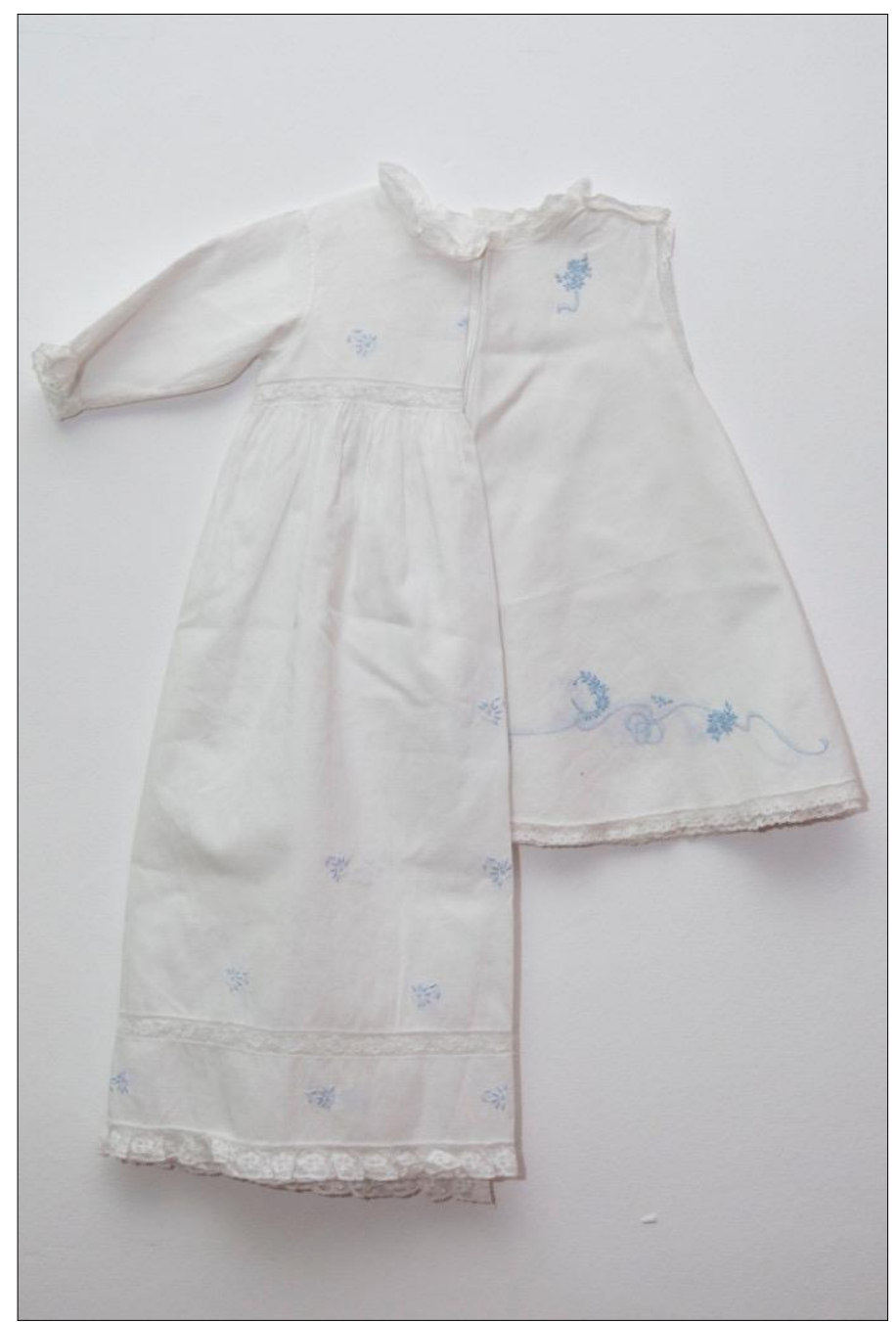

A ação de abotoar vestidos diferentes, juntando-os como uma nova roupa me remete à criança que não tem ainda o domínio do próprio vestir e abotoa erradamente, descasando botões e casas. É esse território do erro, do desacerto que é ativado por essa série de vestidos/objetos. É a proposição da impossibilidade que abre espaço para a experimentação.

\section{Memória e invenção}

Uma reportagem publicada na revista Época em julho de 2014, período em que estava preparando a exposição Vestida de Infância, aponta que o fato de termos dificuldade de acessar memórias da primeira infância é um assunto que há muito intriga a ciência. A reportagem faz menção a um artigo publicado na revista científica Science que propõe uma explicação a esse fato. 
A pesquisa foi desenvolvida por pesquisadores do SickKids, um hospital infantil associado à Universidade de Toronto, no Canadá. Segundo o estudo, crianças pequenas registram lembranças perfeitamente. Em seus cérebros, no entanto, a neurogênese - o processo de criação de novos neurônios - ocorre muito velozmente. Em cérebros mais maduros, a criação de novos neurônios é comumente associada a ganhos cognitivos e benefícios para a memória. Para as crianças, a violência do processo bagunça sinapses a ligação entre os neurônios, por meio das quais as memórias se consolidam. $\mathrm{O}$ número de neurônios cresce tão rapidamente que provoca esquecimento ${ }^{1}$.

O artigo aponta também outras possíveis interpretações para esse esquecimento, inclusive citando a psicanálise freudiana que os considera uma forma de se poupar dos traumas da primeira infância, mas certifica a existência de um mecanismo biológico para o processo. A ciência indica então que para crescer, devemos esquecer.

Atestamos portanto que as memórias da primeira infância não podem ser acessadas, segundo comprovação científica. Pesquisando sobre memória, me deparei com esse trecho do filósofo Walter Omar Kohan, que vai colocar à ideia de memória da seguinte maneira:

De forma semelhante, a memória seria algo da ordem da descoberta, da recuperação, da rememoração, em suma, algo da ordem do não inventado, da des-invenção. Ao contrário, a invenção parece indicar algo novo, que se inicia, que começa, portanto impossível de ser lembrado. A invenção seria algo da ordem da des-memória e a memória algo da ordem do não inventado. Se algo é inventado não poderia vir da memória; se algo vem da memória não poderia ser inventado. A memória e a invenção andariam em direções contrárias, encontradas, desentendidas ${ }^{2}$.

De frente com essa colocação, me lembro imediatamente do livro Memórias Inventadas, do genial poeta Manoel de Barros, que nos propõe uma relação direta entre memória e invenção. $\mathrm{O}$ autor estaria adentrando o território de uma obra memorialista, autobiográfica,ou de uma obra inventada? Não me coloco aqui como uma analista da obra literária do poeta, por completa impossibilidade e desconhecimento necessário para tal. No entanto, como leitora e artista influenciada por suas palavras, me sinto livre para trazer à tona apenas a discussão sobre o título de seu citado livro, como contraponto da descrição proposta por Kohan. Por estarmos no território da arte, é fácil compreender que memória e invenção podem, sim, caminhar juntas. Na arte é possível estabelecer relações diretas e fraternas entre elas. O próprio Manoel de Barros comenta que:

Esse livro Memórias inventadas é uma coisa que a gente vai produzindo com muita preocupação literária. Sendo literária, é muito mentirosa. Há muita mentira nisso tudo, inclusive da invenção. É inventada por isso, porque ela vem de muitos lugares e de muitas infâncias que não sejam a minha só, sabe? A minha só não tem graça³

\footnotetext{
${ }^{1}$ http://epoca.globo.com/vida/noticia/2014/05/por-que-nao-conseguimos-blembrarb-do-comeco-dainfancia-ciencia-explica.html

${ }^{2}$ http://www.educacaopublica.rj.gov.br/biblioteca/educacao/0184.html

${ }^{3}$ www.maxwell.vrac.puc-rio.br/16078/16078 5.PDF
} 
Todos os trabalhos apresentados aqui surgiram de uma pesquisa feita de um encontro com o presente que carinhosamente me foi entregue. Percebo porém que não tenho lembrança de usá-los. O máximo que me resta são poucas fotografias em um álbum de família em que me vejo vestida com alguns deles. E pela simples constatação de que não era possível alcançar memórias apagadas, sem tristeza, parti para a experimentação certa de que essas memórias inalcançáveis me constituem hoje, mas que meu interesse agora se voltava a investigar essas vestimentas. $\mathrm{O}$ que nesses vestidos podia ser experimentado novamente, num tempo presente, sem recorrer a um passado disforme? Como era o contato com o tecido? E os bordados, o que podia fazer com todas essas delicadezas? Seus botões, suas casas, seus tamanhos, tudo isso estava disposto à minha frente. Coloquei então meu corpo a serviço dessas experimentações, pensando o corpo como nosso habitat, o que regula nossas relações com o mundo e com os outros. E ele é coberto por esse singular tecido chamado pele, membrana que estabelece a fronteira entre o dentro e o fora e imprime afecções ao longo da vida. Meu corpo e minha pele foram meus instrumentos para experimentar novamente os vestidos da minha infância. A pesquisa parte daí, resultando em atos performativos registrados em fotografia ou vídeo.

\section{Referências}

BARROS, Manoel de - Memórias Inventadas, Segunda Infância - Editora Planeta São Paulo, 2006

GRUMICHÉ, Mônica Cristina Dutra. Da ideia de Infância em Jean-Jacques Rousseau ou Do "Sono da Razão", Dissertação (Mestrado em Educação). Universidade Federal de Santa Catarina, Centro de Ciências da Educação. Florianópolis, SC, 2012.

PEREGRINO, Giselly dos Santos. A educação pela infância em Manoel de Barros, Dissertação (Mestrado em Letras). Pontifícia Universidade Católica do Rio de Janeiro, Rio de Janeiro, RJ, 2010.

REINALDIM, Ivair. Vestida de Infância - ensaios sobre a imponderabilidade. Disponível em: http://www.claudia tavares.com/vestida-de-infancia-ensaios-sobre-aimponde rabilidade/

KOHAN, Walter Omar. A Infância da Educação: O Conceito Devir-Criança. Disponível em: http://www.educaca opublica.ri.gov.br/biblioteca/e ducacao/0184.html

Manoel de Barros busca o sentido da vida. In: O Estado de São Paulo, Caderno 2, 22 fev. 2008. Disponível em: http://www.re vis ta .a gulha.nom.br/cas te 109.html

A eterna infância de Manoel de Barros. In: O Estado de São Paulo, Caderno 2, 08 abr. 2006. Disponível em http://www.s upers ite good.com/re leitura/te xto.php? mat=362 